\title{
Rethinking the India-Bharat Divide vis-à-vis COVID-19: Implications for a Sociolinguistics of Health Communication
}

\author{
Ajit Kumar Mishra \\ Associate Professor, Dept. of Humanistic Studies, Indian Institute of Technology \\ (Banaras Hindu University) Varanasi, India Email: akmishra.hss@iitbhu.ac.in ORCID: \\ oooo-0003-4839-1699
}

\begin{abstract}
:
Language plays an important role in the dissemination of critical health information across human societies. Taking a cue from the sociolinguistic nuances of the role of language in society, this study probes the India-Bharat divide in the COVID-19 scenario as a potential hurdle to the sense making practices necessary for successful health communication. By delving into the dichotomous linguistic relationship between India and Bharat, this study contends that in order for this sociolinguistic dichotomy to be resolved and health communication to be effective, it is important that all concerned must be in control of the same code. The study raises questions ranging from challenges for health communication with respect to the linguistically diverse population in the country, access to reliable health information, to the problem of incomprehensibility as a barrier to the availability of proper health information. Through qualitative content analysis of the COVID-19 health information terminology mediated through popular Hindi news channels during the first phase of lockdown in India and the corresponding outcome reports across digital platforms, the study analyses the India-Bharat divide and suggests sociolinguistic strategies that can tacitly turn the structural pluralism into an organic pluralism making heath communication in India smooth and discernible.
\end{abstract}

Keywords: COVID-19, comprehensibility, India-Bharat divide, health communication, sociolinguistics

\section{Introduction}

Health communication policies and strategies need to be deeply rooted in the cultural practices, linguistic conventions, and socio-economic conditions of their stakeholders. For health communication to be successful, it needs to be articulated in a nuanced manner so as to make the process of dissemination and assimilation smooth. The acts of articulation and dissemination of vital healthcare information depend greatly on one's ability to use language that is not opaque, alienating and disrespectful (Cayton, 484). There is a need to understand that in healthcare services including health communication it is a prerequisite to use language sensitively as "the meaning of words may be relative, situational, and language dependent" (Bouman et al., p.1).

Health communication practices in India have been subjected to critical scrutiny by organizations and individual researchers in the past. To comprehend the health communication scenario in India, we can review a few important observations derived from the past studies. The World Health Organization (2007) while assessing the healthcare

(C) AesthetixMS 2020. This Open Access article is published under a Creative Commons Attribution NonCommercial 4.0 International License (http://creativecommons.org/licenses/by-nc/4.o/), which permits noncommercial re-use, distribution, and reproduction in any medium, provided the original work is properly cited. For citation use the DOI. For commercial re-use, please contact editor@rupkatha.com. 
facilities in India has remarked, "health status of the population at large in India leaves much to be desired despite having a well-developed administrative system and technical skills." John et al. (2011) remark that though India has made a considerable progress in improving the health of its population in the past sixty years, yet the results do not augur well for its healthcare standards. Further, India's healthcare conditions have been worsened by the shortage of trained, motivated and supported health workers (WHO and GHWA) and this inadequacy requires an urgent and strategic need to integrate innovation and sustainability in the healthcare action plans to address the health workforce challenge (Hazarika). On the other hand, Pati et al. (2012) in their study of the state of health promotion education and health communication in India have observed, "there is no systematic and comprehensive information available for existing teaching, training and capacity building activities pertaining to health promotion in India" (p. 161). Similarly, Patel et. al. (2011) have called for an action plan to achieve universal access to healthcare in India. However, adopting a different perspective Narayan (2013) shifts this focus from the discourses concerning universal access to healthcare in India to the role of language in health communication. He studies the role of language barriers in healthcare in India and suggests, "simple resources such as clinical language phrase books and patient information leaflets for common conditions and procedures in common languages prevalent in the region can be easily produced" (p.237) to overcome the language barriers and ensure effective healthcare in India.

A close look at these studies reveals the core issues that are ailing India in its struggle to ensure quality health care information to its people through effective health communication. These core issues include India's disease profile, health status of its people, healthcare standards, healthcare workforce, health promotion education, health communication practices in the face of diverse linguistic challenges. It also follows from these issues that the idea of universal access to healthcare has received a lot of attention in the past. Previous research concerning healthcare in India has focussed mainly on the need to enhance health workforce and provide healthcare uniformly, but has ignored reaching out to people through communication plans. Communication is crucial to the delivery of quality healthcare information. Despite acknowledging the importance of communication in healthcare, very little effort has been made to approach the issue of health communication in India. It is surprising to see that except Narayan (2013), no other researcher has attempted to approach the implications of language for health communication. Although Narayan (2013) has approached the issues of language barriers comprehensively, he has not focussed on the sociolinguistic aspects of health communication.

Another important issue which has also escaped the critical inquiry of health communication researchers in India is the India-Bharat divide and its implications for the effective communication of healthcare information. Instead of approaching language in health communication as a closed space, we need to see it as a social practice. Therefore, any understanding of the functions of language needs to be based on an insight into its transactional properties. Further, for such an insight to be developed, it is essential to locate the problem of incomprehensibility in the dialectical relationship between India and Bharat. Clémentin-Ojha (2014) traces this problem to a divided identity between India and Bharat. The first article in The Constitution of India starts with, "India, that is Bharat..." which appears to have encompassed the idea of Bharat in India. But the dichotomy persists even today and appears to remain so until the chasm is bridged. The pair, unlike its originally envisaged idea, does not offer any either/or position, instead it pronounces the chasm as an unsurmountable reality. Assuming with Clémentin-Ojha (2014) we can say that India has had an edge over Bharat since independence. 
A recently released report by KPMG India (2020) has not only acknowledged the IndiaBharat dichotomy but also stressed that the dichotomy is likely widen in the wake of the COVID-19 pandemic. Similarly, in his recent opinion article Sudheendra Kulkarni (2020) has also pointed towards the India-Bharat divide in the face of COVID-19 and has also suggested ways to bridge it. COVID-19 has drawn our attention towardsthe possibility of examining health communication strategies through the India-Bharat divide. In the face of COVID-19, one of the biggest health crises of all times, a major barrier that hindered the effective dissemination of health information in India was the chasm and the unsurmountable reality that has existed between India and Bharat.

This paper examines the sociolinguistic aspects of health communication in India with a view to revealing the underlying complexities that are intertwined with the dialectical relationships between "India and Bharat", "reliability and comprehensibility." The aim of this study is to broaden our understanding of the linguistic barriers that are preventing comprehensibility of the stakeholders of health communication in India. The principal argument of the paper is that messages designed for the communication of health need to include the hitherto ignored element of comprehensibility. In the absence of comprehensibility, even reliable information can be missed or misunderstood. Therefore, it is imperative for the designers of health messages to take care of comprehensibility. The paper also argues that a sociolinguistic approach to health communication in India will help the design, delivery, and sense-making processes. By analysing the most circulated COVID-19 words and phrases mediated by television news channels as healthcare messages during the lockdown period in India, the paper reveals how even the accessible and reliable health information was miscomprehended and thus impeded India's fight against the pandemic. The paper suggests that an understanding of the dichotomies mentioned above will act as the first essential step towards strengthening India's health communication action plan.

\section{Methodology}

Design and Procedure: This research has used a qualitative methodology (Berg, 2001, DowneWambolt, 1992). It uses qualitative content analysis techniques to reveal distinct thematic patterns in the collected data. The concept of driving health communication through popular news media during a health crisis is explored with an objective to examine the occurrence of specific terms in the data and their implications for a greater insight into the health communication practices in India.

Sampling: This paper uses two data sets collected from two different blocks of mediascape. The principal reason behind the collection of these two comparative data sets is to analyse with the help of the second data set the outcome of the health information communicated through the first data set. The first data set was collected by using purposive sampling techniques. Prime-time one-hour news reports communicating preventive healthcare information in the most watched Indian television news channels in Hindi (ABP News, Aaj Tak, R. Bharat, and Zee News) were closely watched for a period of 21 days (25 March 2020 to 14 April 2020) spanning the first phase of lockdown in India and were transcribed for the purpose of further analysis. The second data set was collected from the text-based multiple digital media outcome reports of the preventive healthcare information communicated through the first data set. The COVID-19lockdown period was selected for data collection because of two major reasons: First, a pandemic of the magnitude of COVID-19 is the best time to test the efficacy of health communication strategies; Second, during this period the viewership for news genre surged as people relied greatly on the healthcare information circulated through the news media (ETBrandEquity). 
Coding: A list of codes for the variables in the first data sets was devised. Each word/phrase meeting the criteria for health information was coded and categorised. The following three categories emerged: Distancing and enclosure: The communication of preventive healthcare involving COVID-19 revolved around the predominant idea of distancing and enclosure. Words and phrase like Social distancing, Quarantine, Isolation, Containment zones, Hotspot ssurfaced as the most frequently and emphatically circulated words and strategies to ensure critical protection against the virus. Typology: The messages categorised every citizen into a distinct typology. Words like Symptomatic patients, asymptomatic patients, super spreader emerged as the most powerful way of classifying humans in the face of the virus attack. Personal care: The messages emphatically communicated the importance of personal care as a potent method to counter the spread of the virus. The most frequently communicated words were Mask, Sanitizer, Handwash.

Analysis: A qualitative content analysis of the implications of the codes and the terms devised in first data set vis-à-vis the impact of those codes and words in terms of users' perceptions and responses as reported in the second data set was done. The analysis revealed that the terms in the distancing and enclosure code evoked a general sense of distrust, fear, forced confinement, uncertainty, shame and guilt. Similarly, the terms in the typology code also evoked a general sense of distrust, suspicion, and even hatred. A content analysis of the outcome reports revealed that users' negative responses to the preventive healthcare terms in the abovementioned codes were largely due to the incomprehensibility of those terms and their inability to connect with the stakeholders. However, unlike the negative responses to the terms in the first two codes, the terms in the personal care code derived a much positive response.

\section{Findings}

Around 21 hours of prime-time news communicating preventive healthcare messages in the face of COVID-19 were watched, and around 20 digital media reports over the outcome of the abovementioned communication was read. The qualitative content analysis of the data sets yielded the following results:

1. Two strands of population emerged when it came to the comprehensibility of the preventive healthcare messages communicated through television. The outcome reports implied that not everyone found the COVID-19 terminology to be problematic, and that there are also a large number of people who were comfortable with the COVID-19 terminology.

2. Stakeholders who displayed distrust and found it impossible to connect with the terms in the first two codes did so because of the negative connotations of confinement and negative social image associated with the terms. Some serious reservations against the concepts of social distancing, containment, spreaders and super spreaders were also displayed by the stakeholders.

3. The most important concepts that resulted from the analysis were incomprehensibility and esoterism. The fact that there was widespread acceptance of the terms in the personal care code strengthens the universal access to the same code thesis.

\section{Discussion}

Comprehensibility is key to successful communication and behaviour change, and health communication is no exception. For any health communication strategy to be successful in India, a greater insight into the linguistic, cultural, and socio-economic diversities needs to be developed. The qualitative content analysis of the most frequently communicated COVID-19 terms and their impact on a large number of people supports the need for a sociolinguistic 
framework for health communication practices in India. The study revealed the subtlety and nuances of language, when subjected to social transactions, can generate opposite responses. The results inform us to look for a language framework for the design and delivery of inclusive and equitable health information. First, it follows that the creators and/or distributors of healthcare terminology need to be aware of the fact that language can promptly become incomprehensible and baffling if not designed with care. The second major pointer is that language is performative and impactful, hence it is essential to ensure that terminological frameworks are designed to accomplish the set goals. A third pointer is that more than providing just ready access to reliable health information, it is important to enable users to discern and assimilate the information received. However, the design and the delivery processes for health information are complex as health communication draws on a variety of disciplines including sociology, anthropology, mass education among others (Bernhardt, 2004). A potent method to address this complexity is to weave an action plan integrating an inclusive and comprehensible language and a sound implementation strategy in order for health communication campaigns to be effective.

Our understanding of the chasm between India and Bharatas the one between fluency and disfluency will also help us understand the dialectical relationship between accessibility and comprehensibility in relation to health communication. Since behaviour change is the ultimate goal of health communication, the linguistic items used in such communications should not suffer from "processing fluency" both linguistically and culturally. Health messages, as the results show, will be received and assimilated only when they do not thwart the sensemaking processes.

\section{Conclusion}

This study was conducted to validate the role of sociolinguistics in the effective designing and delivery of health information in India. An understanding of the diverse linguistic and cultural structure of India can help health communicators discern the impact and implications of the linguistic items across speech communities. The study establishes that without integrating the social, the cultural, and the linguistic meanings health messages will struggle to achieve their expected results. Sociolinguistics and health communication are closely allied disciplines in the sense that the actors involved in the process of communication not only exchange information with the help of language, but also engage in a sensemaking process. Looked at from the vantage point of sociolinguistics, health communication is implicated in the dichotomous relationship between high prestige and low prestige language leading to multiple barriers to the dissemination process. As a result, these highly ignored linguistic nuances are keeping health communication practices from improving health literacy through the dissemination of health information in India.

\section{References}

Berg, B.L.(2001). Qualitative research methods for the social sciences. Boston: Allyn and Bacon.

Bernhardt, J. M., Weaver Lariscy, R. A., Parrott, R. A., Silk, K. J., \& Felter, E. M. (2002)Perceived barriers to internet-based healthcommunication on human genetics. Journal of Health Communication, 2002, 7(4), 325-340.

Bouman, W. P., Schwend, A. S., Motmans, j.,Smiley, A., Safer, J. D., Deutsch, M. B., Adams, N. J., \& Winter, S. (2017). International journal of transgenderism, 18(1), 1-6.

Cayton, H., (2006).Journal of The Royal Society of Medicine, 99(October), 484. 
Clémentin-Ojha, C. (2014). 'India, that is Bharat...': One Country, Two Names.South Asia Multidisciplinary Academic Journal. 10. Retrieved from https://journals.openedition.org/samaj/3717.

Downe-Wambolt, B.(1992). Content analysis: method, applications and issues.Health Care for Women International, 13, 313-321.

ETBrandEquity. (2020, April 2). Coronavirus impact: TV viewership continues to surge. Economic Times, Retrieved from https://brandequity.economictimes.indiatimes.com/news/media/coronavirus-impact-tvviewership-continues-to-surge/74949741

Hazarika I. (2013). Health workforce in India: Assessmentof availability, production and distribution. WHO South-East Asia Journal of Public Health,2, 106-112.

John TJ, Dandona L, Sharma VP, \&Kakkar M. (2011). Continuing challenge of infectious diseases in India.Lancet. 377(9761):252-269.

KPMG. (2020). COVID-19: The many shades of a crisis. https://home.kpmg/in/COVID-19.

Kulkarni, Sudheendra. (2020). Work from Bharat, Work for Bharat: How Digitech is Doing 'BharatIndia Jodo', Retrieved from https://www.news18.com/news/opinion/work-from-bharat-workfor-bharat-how-digitech-is-doing-bharat-india-jodo-2661149.html

Narayan, L. (2013) Addressing language barriers to healthcare in India.The National Medical Journal of India, 26(04), 236-238.

Patel, V., Kumar, A. K., Paul, V. K., Rao, K. D., \&Reddy, K. S. (2011). Universal healthcare in India: Thetime is right. Lancet, $377,448-449$.

Pati, S., Sharma, K., Zodpey, S., Chauhan, K.\& Dobe, M. (2012). Health Promotion Education in India:Present Landscape and Future Vistas.Global Journal of Health Science, 4(04),159-167.

World Health Organization. (2005). Burden of Diseases in India. Retrieved fromhttp://www.who.int/macrohealth/action/NCMH_Burden\%20of\%2odisease_\%2829\%2oSep \%202005\%29.pdf

World Health Organization. (2007). Health Work Force in India. Retrieved from http://www.whoindia.org/LinkFiles/Human_Resources_Health_Workforce_in_India__Apro7.pdf

World Health Organization,\& Global Health Workforce Alliance. (20o8). Scalingup, saving lives: task force for scaling up education and training forhealth workers.Retrieved from https://www.who.int/docs/default-source/health-workforce/scaling-up-savinglives.pdf?sfvrsn=aoo71de3_2

Ajit Kumar Mishra is an Associate Professor of English in the Department of Humanistic Studies, Indian Institute of Technology (BHU) Varanasi. His research interests are narrative studies, visual culture, and communication for life, work, and health. He is particularly interested in finding ways to navigate the communication challenges posed to young researchers in India. He is currently researching the prospects and challenges of research communication in Indian academies. 